\title{
O semioticista da história: entrevista com Jorge Lozano
}

\section{Fábio Sadao Nakagawa}

Doutor; Universidade Federal da Bahia, Salvador, BA, Brasil.

fabiosadao@gmail.com

\section{Regiane Miranda de Oliveira Nakagawa}

Doutora; Universidade Federal do Recôncavo da Bahia, Santo Amaro, BA, Brasil. regianemo@uol.com.br

\section{Resumo}

Nesta entrevista, Jorge Lozano, professor catedrático do departamento de Jornalismo e Novos Meios da Universidade Complutense de Madrid, fala sobre sua concepção da história enquanto construção discursiva e do documento histórico segundo o ponto de vista semiótico. De acordo com tal perspectiva, é a pertinência que nos permite situar se um determinado texto cultural pode ou não funcionar como um documento. Também aborda sua parceria com Umberto Eco e a importância da ideia do "leitor modelo" na obra do autor italiano e a atualidade desse conceito para entender os meios digitais. Por fim, situa de que maneira a semiótica pode contribuir para construir uma inteligibilidade do presente e a dimensão política que envolve qualquer prática pautada pela compreensão do funcionamento dos signos na cultura.

\section{Palavras-chave}

Semiótica. Discurso Histórico. Leitor modelo. Umberto Eco.

No prólogo do livro El discurso histórico, de Jorge Lozano, Umberto Eco afirma que todo exercício de análise semiótica realiza-se sobre algum tipo de ausência ou, ainda, de distância. Por isso, a história se constituiria num campo de excelência para o estudo da semiótica visto que, por meio dela, seria possível, de forma inferencial, reconstruir o passado com base em signos que persistem no presente, por mais tênues que sejam seus rastros. 
Tal é o exercício de intelecção que tem pautado o trabalho do prof. Jorge Lozano, catedrático do departamento de Jornalismo e Novos Meios da Faculdade de Ciências da Informação da Universidade Complutense de Madrid (UCM). Mais conhecido no Brasil pela obra Análise do discurso. Por uma semiótica da interação textual, redigido em coautoria com Cristina Peña Marín e Gonzalo Abril, e pelo prólogo da edição espanhola publicada pela Gedisa do livro Cultura y explosión, de Iuri Lotman, o prof. Lozano possui um consistente trabalho voltado ao estudo da construção do discurso histórico e do documento histórico pela perspectiva semiótica e pela retórica, cujos preceitos mantêm estreita relação, tal como elucida o semioticista da cultura Iuri Lotman.

$\mathrm{Na}$ trajetória recente do prof. Lozano, cumpre também ressaltar o trabalho realizado pelo grupo liderado por ele, o GESC, Grupo de Pesquisa em Semiótica da Cultura, que tem se dedicado, sobretudo, ao estudo da obra de Lotman. Inclusive, em outubro de 2018, na UCM, foi organizada uma importante jornada internacional, intitulada Lotman e a história do presente, face o aniversário de 25 anos de falecimento de Lotman e a publicação do livro Cultura y explosión.

Assim, nesta entrevista, realizada em janeiro de 2019 em seu gabinete na UCM, o prof. Lozano fala sobre sua compreensão da história e do documento pela perspectiva semiótica, situando o segundo em virtude da sua pertinência. Tendo em vista os 40 anos da publicação da obra Lector in fabula por Umberto Eco, Lozano relata sua convivência com o autor italiano durante o processo de escrita da referida obra e a atualidade do conceito "leitor modelo" para compreender a relação dos usuários com os meios digitais. Por fim, situa de que maneira a semiótica pode contribuir para construir uma inteligibilidade do presente e a dimensão política que envolve qualquer exercício de intelecção pautado pelo estudo dos signos na cultura.

\section{Em sua opinião, quais são as principais contribuições da semiótica para a área da comunicação?}

Defendo que sem as investigações e os estudos desenvolvidos lentamente pela semiótica ao longo de todo o século XX, a comunicação, na atualidade, não seria como é. Há muitos sabores e saberes incorporados na comunicação, provenientes da semiótica, como, por exemplo, as importantes contribuições da Teoria da Enunciação. 0 próprio esquema da comunicação de índole informacionalista tem sido modificado pelas polifonias e outros 
componentes que somente são estudados no campo semiótico. A redefinição dos atores e a consideração da narratividade sem a narração como princípio de inteligibilidade contribuíram para consolidar impressões comunicativas que, antes, funcionavam exclusivamente como efeitos de transmissão e sinais de informação. A própria comunicação é semiótica e os desenvolvimentos da semiótica são de índole comunicacional.

\section{Qual é seu diagnóstico sobre os estudos semióticos na atualidade?}

Sou muito otimista. Acredito que a história da semiótica, e digo isso quase com Umberto Eco, foi interrompida durante um período. Trata-se de um saber que tinha vinte e tantos séculos, que provêm dos estoicos, dos galenos, Hipócrates, etc. Tal interrupção se deu em virtude do seu próprio vigor e da falta de divulgação. Porém, no século XX, assistimos a uma espécie de imperialismo semiótico. Nos anos 60 e 70, em Paris, tudo era semiótica: a psicanálise de Lacan, a antropologia de Levi Strauss, a Teoria da Comunicação, a Linguística. Tudo era semiótica e, como em política, isso trouxe uma inversão e, então, o surgimento de dois novos campos: o cognitivismo e os estudos culturais, que intentaram substituir o imperialismo semiótico. 0 cognitivismo hoje, uma vez feitos mapas e algoritmos... Acredito que o problema é que a linguagem segue sendo de Górgias, de transformação, manipulação, ação e não apenas representação de mundo como entende os cognitivistas, portanto, segue vigente, e cada vez mais, a questão sobre como somos capazes de transformar o outro, de convencê-los. Por outro lado, os estudos culturais não possuem método. Curiosamente, de acordo com meu ponto de vista, os estudos culturais europeus, incluindo os alemães, que são um pouco diferentes e, claro, os anglo saxões, pois poderia citar qualquer um deles; a única condição sine qua non para todos eles era não citar Lotman que, efetivamente, não foi mencionado por ninguém relacionado aos estudos da cultura. Suspeito que isso se deve ao fato de que Lotman e seu grupo da Escola de Tártu-Moscou tinham um método, e esse método irrita muito. Então, de acordo com os estudos culturais, se estuda a cultura sem método, ao passo que a semiótica da cultura se ocupa da cultura por meio de um método e, aí, há uma espécie de enfrentamento. Enquanto que, para os estudos culturais, digamos, a atenção volta-se a certos temas, um pouco de moda, sem tantas variações, nós, como aprendi com Paolo Fabbri, somos ecléticos em nossos objetos, porém, não em relação ao método. Temos um método semiótico e podemos analisar qualquer objeto com maior ou menor fortuna crítica, dependendo do conhecimento do pesquisador. Por outro lado, eles [os 
estudos culturais] pensam que qualquer objeto está submetido a um ecletismo metodológico pelo qual não se sabe muito bem o que se está analisando. Nós não analisamos economicamente um objeto, nem sociologicamente. Nós o analisamos semioticamente, quer dizer, tratamos de estabelecer as diferenças e as posições.

\section{Em seu livro, El discurso histórico, o senhor trabalha com uma concepção semiótica da história. Poderia falar um pouco sobre essa ideia?}

A razão pela qual me dediquei à história é de uma banalidade extrema. Eu era licenciado em história e estava estudando semiótica em Bolonha. Então, digamos que me ocupar da história pela perspectiva da semiótica me parecia normal. Eram os anos [19]70 depois de Franco, quando eu pude ir estudar na Itália. Da mesma forma que se usa a cronologia antes e depois de Cristo, nós, espanhóis, dizemos antes ou depois de Franco. É claro que havia o predomínio dos estudos literários. A semiótica literária era a que havia desenvolvido novos paradigmas. Ocupar-se da história era uma loucura absoluta, sobretudo em um momento em que estávamos sob a égide da seção sexta da École des hautes études en sciences sociales e das grandes figuras provenientes da Escola dos Annales, como Le Goff e outros. Havia historiadores que, entre aspas, desdenhavam da semiótica, vista por eles como uma disciplina fundamentalmente sincrônica que havia abandonado a diacronia. Mais especificamente, quando me enfrentei com textos, quero dizer, com os objetos textos, comecei a estudá-los e estava interessado em certas aproximações proto-semióticas como ocorria, por exemplo, com todos os autores que vinham da França: havia François Hartog, Le Goff, o grandíssimo De Certeau; e certos comentários que, mais que outra coisa, havia feito sobre história Marshall Sahlins. Da Alemanha, tardiamente descobri Koselleck e sua semântica histórica. Também me deparei com um texto que me deslumbrou desde o princípio, pois se aproximava ao fenômeno da história, porém, o livro é muito posterior, Tempo e narração, de Paul Ricoeur. Então, eu tinha dois interesses. Primeiro: com o quê comparar um texto de história? Podia compará-lo com qualquer um, por exemplo, era uma das coisas que vi com Eliseo Verón, que dizia que todo texto deve ser comparado a outro texto, ainda que este último seja um texto ideal. Inclusive, eu cheguei a tentar compará-los com uma receita de cozinha, quase como um exercício de análise. Em segundo lugar, me dei conta que os textos de história possuíam uma reflexividade extraordinariamente 
interessante, pois eles mesmos se autodefiniam em seus procedimentos. Eles não se designavam como um texto de ficção, tampouco como um produto da imaginação e, assim, havia toda uma construção para buscar uma justificativa ou legitimar um fazer que estava alijado da ficção. E qual era o ponto-chave para entendê-los? Eles se faziam inteligíveis por meio da narração, que não implicava, precisamente, em atender às formas narrativas, o que nos levaria à discussão dos gêneros literários, mas envolvia o problema de uma inteligibilidade, que se tratava de uma questão retórica. Com isso, encontrei-me muito satisfeito e tratava de ver, ao mesmo tempo, quais eram as grandes estratégias utilizadas pelos textos históricos. Inclusive, minha tese de doutorado chamava-se Estratégias persuasivas e discursivas do texto de história. Tais estratégias residiam fundamentalmente na construção de um texto feito para simular o máximo de objetividade que pressupunha, sem mais nem menos, cancelar a marca de subjetividade que, digamos, era o aparato formal da enunciação de Benveniste. E me encontrei extraordinariamente cômodo e, bem, foi uma tese enorme. Logo tive a sorte de publicá-la pela Alianza, uma excelente editora espanhola, assim como em italiano, na coleção de minha preferência, a Sellerio, com prólogo de Umberto Eco.

Sempre suspeitei que tanto êxito era porque os historiadores não viam em mim um perigo. Enfim, me ensinou muito, digamos, o modo como os próprios discursos não apenas pretendem fazer determinadas coisas, mas também se autodefinir, estabelecer certas regras internas. No âmbito da história cultural, surgiu o grande historiador Krzysztof Pomian, que criou o conceito de semióforo. Acredito que é indicativo o que ele diz, que podemos ver um objeto dentro da história cultural, de modo que um livro é um livro, mas também pode ser uma grande obra literária. Digamos que se trata de uma transformação semiótica, daí o semióforo. Acredito que é uma concessão que os grandes historiadores têm feito à semiótica, inclusive, suspeito que eles a leem clandestinamente e não assumem. Estou convencido que François Hartog conhece muito bem a semiótica, pois ele está em Paris e sabe perfeitamente quais são os grupos. Custa muito reconhecer o semiólogo, precisa ser um extravagante como Bruno Latour, ainda que Latour seja um sociólogo e os cientistas tampouco o querem muito. É preciso haver interstícios e situações de encruzilhadas para que ocorra esse reconhecimento, como dizia Lotman. Porém, creio que a grande herança da semiótica é que ela não necessita ser reconhecida, mas sim incorporada. Nos incorporam em outras disciplinas. 


\section{E como se pode entender a ideia de documento histórico por meio da semiótica?}

Impressionou-me muito uma definição, assim en passant, do grande Lucien Febvre quando, em 1929, foi criada a Revue des Annales (Les Annales d'histoire économique et sociale). Ele dizia que a história é feita com documentos, quando eles saem e, quando não saem, qualquer coisa pode ser um documento. E o que é um documento? É um texto que serve para contar uma história, é um pretexto para contar uma história, são uma série de signos cuja descrição, digamos, ou sua decodificação, permite entender algo. 0 interessante é a ideia de que são a narração e as leis do discurso que tornam um documento pertinente ou não. Hoje, por exemplo, acredito que, por meio dessa perspectiva, podemos enfocar os big datas, criando a ilusão fetichista de que há mais dados, mais informações, mais democracia, mais ilustrações... O interessante é, e isso nos ensina a semiótica, o conceito fundamental de pertinência. Quais dados são pertinentes? Para que servem? Nem todos os dados valem, alguns não servem para nada. É a pertinência que os atravessa e decide.

\section{Em 2018, o grupo GESC (Grupo de estudo em Semiótica da Cultura), liderado pelo senhor, completou dez anos de atuação. Quais são as principais contribuições do grupo para o desenvolvimento científico da semiótica?}

Percebi que havia alunos que não tinham dificuldade em me seguir, por assim dizer, e houve um momento em que vinha muita gente aos meus seminários. Então, decidi que era melhor dar a eles uma certa estrutura, colocar um carimbo, como dizia Greimas. Assim, criei o GESC na Fundação Ortega-Marañón, vinculado à Universidade Complutense de Madrid. Era lá que eu havia feito minha tese, onde estava a biblioteca Ortega e se publicava a Revista de Occidente, em que fui secretário de redação. Recordo-me de um passeio em Veneza com Fabbri, em que lhe dizia que a semiótica exige um método, inclusive, para adequar a própria mirada. Queria fazer um grupo bastante dinâmico devido aos temas a serem discutidos e por minha opção, sem fissuras, à Lotman e à Semiótica da Cultura. Assim, começamos a ler certos textos e a realizar seminários de formação que ocorreram com muito entusiasmo. No 
ato inicial, Umberto Eco nos abençoou na Fundação Ortega. Depois, realizamos um grande evento, com Uspenski, Fabbri, Omar Calabrese e eu no círculo de Belas Artes, que teve um público excepcional. Desde então fizemos dois bons congressos na Fundação Ortega, em 2010 e 2013, cujo responsável foi Marcello Serra. Nesses anos, insisto, temos recebido muito apoio de Paolo Fabbri, Uspenski, do grupo de Omar Calabrese e muitos outros italianos. Na França, tem sido Fontanille, Denis Bertrand e Landowski, fundamentalmente. Desde sua criação, pesquisadores vinculados ao GESC realizaram teses de doutorado, projetos de pesquisa e os referidos congressos. Também houve nossa participação na Associação Semiótica Espanhola e na criação da Associação Ibérica de Semiótica. Também temos recebido um forte apoio da Revista de Occidente.

\section{O senhor acredita que é possível pensar em uma semiótica política?}

Minha aproximação com a semiótica foi muito ingênua, e imagino que isso aconteceu com muitos outros, pois deveu-se somente por uma preocupação política em utilizá-la como um instrumento crítico de análise e de desmascaramento dos textos e da ideologia subjacente ou explícita presente em qualquer discurso político. Eu devorava os textos de Eliseo Verón sobre ideologia. Antes mesmo de estudar em Bolonha, minha primeira discussão sobre isso foi com Paolo Fabbri. Disse-lhe que queria averiguar a ideologia dos textos por meio da semiótica. Era outubro ou novembro de 1976. Muito carinhoso, porém, com certo desdém, Paolo disse-me: "a ideologia nos textos, a ideologia nos textos... Onde você a situa: em uma palavra, em uma frase, em um texto? Falaremos sobre isso quando terminar o curso". Com o tempo, já amparado pela semiótica, comecei a me dar conta do equívoco e da inutilidade prática do nível de denotação versus conotação. Pensávamos que, e eu ingenuamente, no meu grau zero em semiótica, que a ideologia seria uma suposta conotação. Então, a primeira lição que recebi é que os textos que poderiam veicular os mesmos valores ideológicos, entre aspas, também poderiam produzir efeitos diferentes, ou textos que possuem valores claramente contrários, podem produzir o mesmo efeito. Dessa forma, como primeira conclusão, eu teria que considerar todo problema político ideológico ou ideológico político, considerando os efeitos de sentido que produziam. Evidentemente, eu acredito que a semiótica é política, da mesma forma que é crítica. Daí minha discordância a Theo Van Dijk que, em seus últimos trabalhos, formulou a expressão Análise Crítica do 
Discurso. Uma análise é sempre crítica e uma análise do discurso está baseada na crítica, que não é outra coisa senão o estabelecimento de diferenças. Assim, falar de uma análise crítica do discurso é quase um pleonasmo. Acredito que a semiótica é política, e essa é a única vez em que cito Morris, que tinha uma preocupação quase militante de mostrar que, efetivamente, a justificativa, a licitude e a legitimidade da semiótica provêm de uma intervenção no social que é obviamente política. Entendo que a semiótica não pode não ter intervenções políticas. Neste momento, por exemplo, se estamos falando de Lotman, a política é um elemento fundamental na formulação de uma tipologia do tempo presente e atual. Face a, digamos, todos os híbridos, contaminações e confusões de nossa sociedade, passando de remakes em remakes e problemas com a memória; pode-se considerar que o mero fato de fazer uma tipologia cultural do presente é uma ação política de grande envergadura. Dizer que a semiótica é política é como dizer que a semiótica tem a ver com a comunicação. Todos os desenvolvimentos empíricos da semiótica estão correlacionados com a comunicação, de modo que não cabe uma semiótica que não tenha uma dimensão comunicacional e vice-versa. Veja, por exemplo, a preocupação com a manipulação, como uma espécie de fazer-fazer ou de intervenção obviamente política.

\section{O senhor trabalhou muitos anos com Umberto Eco e, este ano, se celebra} o aniversário de 40 anos da publicação da obra Lector in fabula. Quais são as principais contribuições dessa obra e do pensamento semiótico de

\section{Umberto Eco?}

Quando celebramos o aniversário do Tratado Geral de Semiótica, eu e Fabbri reparamos o lugar destacado e a atenção que Umberto Eco deu à ideologia. Eu estava com Eco enquanto ele estava preparando o livro Lector in fabula. Em certas análises que fez, chamou a nós, estudantes, para ajudá-lo. Vejo que o momento era extraordinariamente interessante. Naqueles anos, entre 76 e 77, Eco fez duas coisas fundamentais em sua trajetória. Ele já havia terminado Tratado Geral de Semiótica, escrito originariamente em inglês, e estava obcecado com um dos conceitos-chave para o desenvolvimento da análise semiótica: o código. Um pouco antes, os conceitos de codificação e decodificação também tinham se expandido: em 73, na Inglaterra, Stuart Hall escreveu Encoding and decoding in 
the television discourse; Basil Berstein falava de códigos elaborados e restringidos; Barthes estava fazendo S/Z, em que tratava de códigos, incluindo o código proairético; Lotman teorizava sobre códigos sociais e culturais. Havia uma pressuposição no ambiente semiótico, de modo que todas as variações e tipologias que se poderiam fazer em torno do destinatário da comunicação estavam baseadas num ponto de decodificação. Eco havia pesquisado em todos os campos possíveis, algo que somente ele sabia fazer: a teoria da informação, a cibernética, a discussão sobre o canal, a função do código proposta por Jakobson, etc... A possibilidade de ver que, e logo se desmontou, a língua como um código e a mensagem como parole, para fazer uma relação entre a teoria da comunicação e Saussure. Em suas maravilhosas análises e, mesmo havendo militado na guerrilha semiológica que ele havia proposto, o código é um conceito guarda-chuva. Não esqueçamos, por exemplo, e essa é minha perspectiva, da importância do princípio de modus ponens. Eco não pode negar, digamos, que toda a sua genealogia está em Santo Tomás de Aquino e, da lógica medieval, retomou a ideia de modus pones. Toda a sua bibliografia está marcada por essa atitude proposicional e lógica; é onde vai lutar precisamente naqueles anos. Porém, este conceito está saindo das nossas mãos, pois não cumpre os requisitos necessários para uma boa análise semiótica. Como discípulo de Eco, uma expressão que eu já disse mil vezes, e insisto, é que a codificação e a decodificação são uma condição necessária, mas não suficiente. E, em parte, devo isso a ele e ao campo em que eu trabalhava. Eco começava a se dar conta que a operação de decodificação não era suficiente, como no esquema utilíssimo da comunicação, porém, cheio de falhas, de Jakobson, que é um semiólogo excepcional. A necessidade de compartilhar um código comum é, digamos, uma pretensão, porém, não é suficiente.

Lembro, por exemplo, quando Christian Metz dizia que, num ato de decodificação, ante um enunciado tão simples como "cale-se, por favor", junto ao código da língua natural existe, por exemplo, o código da cortesia. Naquela época, junto com Fabbri, Eco também falava de subcódigos. Então, o que faz alguém quando lê um texto? Não vai ao dicionário, mas ativa sua enciclopédia, ou seja, todo o background, toda a acumulação, todos os conhecimentos que possui. Nesse aspecto, há um ponto de inflexão na obra de Eco, do código para a enciclopédia. Eco ainda faz uma contribuição de uma clarividência extraordinária quando diz que, no ato de leitura, também não basta ativar a enciclopédia, pois há dois modos ante um texto: em uso e em interpretação. Em uso, posso usar um texto como quiser, com todas as enciclopédias. Por outro lado, a interpretação tem limites. 0 semiólogo não é um desconstrucionista. Estamos contra a desconstrução enquanto deriva 
interpretativa. Posso passar de um lexema a outro, a outro, a outro, porém, nada nos autoriza a delimitar o primeiro e o último. Não podemos aceitar que Jack, o estripador, se justifique dizendo que assassinou uma série de mulheres em Paris em decorrência da leitura da bíblia. A bíblia permite algumas coisas, outras não. Então, aí, se coloca o grande Umberto Eco, que começa a esmiuçar seus próprios conceitos. Código é substituído por enciclopédia. E, aqui, faço um parêntesis. Cláudio Paolucci, a quem muito estimo, e que se considera herdeiro de Eco, acredita que haveria pontos de conexão entre o conceito de enciclopédia e a semiosfera, definida por Lotman. Se me perguntarem o que penso, eu diria que não. Não porque, precisamente, um dos grandes problemas da enciclopédia é tudo o que nela se pode coletar, por outro lado, na semiosfera, há o que escapa pelos seus filtros, o que se expulsa, além de desgastes internos e a intervenção do observador do espaço semiótico.

A enciclopédia é quase uma espécie de coleção de termos. A enciclopédia tem mais a ver com a biblioteca de Borges do que com a semiosfera. Evidentemente, há comparações e analogias que podem permitir, sobretudo, a ideia de coexistência de diferentes sistemas da própria coleção. Em Lotman seriam extratos, em Umberto, creio que seria acumulação. Ao mesmo tempo, Eco segue contestando a desconstrução, contestando o cognitivismo, inclusive, ele começa a ler autores que, a priori, não lhe eram muito simpáticos. Porém, era sua capacidade enciclopédica... Então, ele se dá conta que nos esquemas da comunicação segue vigente, como esquema, em sentido kantiano, a tríade emissor, mensagem, receptor, o que é uma banalização. Na verdade, são os três livros da retórica de Aristóteles: ethos, logos e pathos.

A atenção dos estudos de Eco está no leitor. Leitor implícito, arte leitor, leitor de todo o tipo. Ele fazia o que mais gostava, ou seja, todas as listas possíveis. Lembro-me de haver visto uma lista de 500 definições de leitor: implícito, explícito, sucedâneo, amorfo, anamórfico, etc. E este texto que me pareceu admirável e que consegui publicar na Revista de Occidente praticamente ao mesmo tempo em que foi editado pela primeira vez, intitulado El extraño caso de la intentio lectoris, em que dizia que é preciso ver também a intentio operi, a intentio auctoris e, digamos, como sempre, havia a tendência a uma espécie de compromisso histórico, que ele tanto apreciava. E, aí, é quando aparece algo que é extraordinário: o leitor-modelo. Como éramos estudantes malévolos e sempre discutíamos com ele que, por sua vez, era de uma generosidade extrema; quando o questionamos sobre o referido conceito ele disse uma frase que ficou em suspenso: "quando falo de autor e leitor, com maiúscula, não estou falando de sujeitos empíricos, mas, sim, de estratégias textuais". 
Justo quando escreve o Tratado de Semiótica Geral, ele trabalhou com um autor que havia lido muito bem, que atua na filosofia da linguagem e na filosofia analítica, que é Paul Grice, autor de Logic and conversation, que estabelece, à maneira de Kant, os princípios regulatórios, os princípios de cooperação... Ele diz que o social se concentra na conversação para que uma conversação funcione, as famosas máximas conversatórias, em que utiliza as categorias kantianas: quantidade, qualidade, relação... Eco logra unir, digamos, uma ideia de princípio de cooperação para a necessidade de que, se não há uma estratégia textual, essa figura, essa configuração discursiva denominada por ele como leitor modelo, à diferença de um leitor empírico, o texto ficaria, exclusivamente, como um flatus vocis. 0 único modo para que se ative o significado é a estratégia textual, digamos, cooperativa. Em definitivo, é a ideia de que o texto, e isso, considerando também os grandes desenvolvimentos da semiótica contemporânea pós-estruturalista etc., como diz Eco, é uma máquina preguiçosa, que necessita de um leitor modelo.

Porém, isso envolve uma interpretação que, por sua vez, está submetida a uma série de regras, limites e limitações. Sempre digo a meus alunos que um dos maiores ensinamentos de Eco é que, segundo ele, ninguém entra no mundo do texto bocejando... É preciso fazer um trabalho, um trabalho de interpretação e ajustar-se a algumas regras para controlar sua enciclopédia e, ao mesmo tempo, investir-se desse leitor modelo, apreender o que é pertinente, o que não é pertinente. Assim, acredito que ele realizou grandes avanços e é uma linha de investigação estupenda, sobretudo porque, no fundo, acredito que Eco é um pouco popperiano, no sentido da falseabilidade: não sei se, ao final, uma leitura é correta, porém, sei que há leituras equivocadas. Eco usava a palavra sentido como sentido de direção proibida. Dessa forma, há coisas na linguagem, e ele dirá muito depois com Kant e o Ornitorrinco, há coisas que não se pode dizer. Isso me parece uma ideia incrível e, digamos, essa limitação é uma consequência de um exercício semiótico dentro da hermenêutica da interpretação. Há limites, há sistemas de regras, que não te levam ao dicionário, pois trata-se de uma questão relacionada à interpretação. Eco estava enormemente preocupado em não reduzir a atividade de recepção de um texto a um sistema de regras. Kant e Ornitorrinco é um grande livro que produziu muita perplexidade e, acredito, com o tempo, as coisas foram se clarificando. Há somente dois modos de ver a linguagem. Um é a linguagem como representação do mundo e isso permite, por exemplo, que os cognitivistas façam mapas, redes e todas essas coisas. Porém, há coisas que provêm da velha retórica, tal como a ideia de linguagem como ação e como transformação do outro. 
Em Kant e o Ornitorrinco, Eco enfatiza a questão do contrato, cuja importância decorre sempre da suspeita de que um significado que você expõe pode ser recebido de outra maneira. Acredito que, à luz de todas essas leituras, estamos em condição de dizer que a comunicação não começa com o emissor, tampouco ocorre da esquerda para a direita, de forma unilateral. Estamos lendo ao revés, o que envolve a consciência de que o leitor pode ter códigos diferentes da emissão. Agora, qualquer estratégia de comunicação começa pelo outro, enquanto que, antes, se lançava uma mensagem e se esperava que o outro tivesse o mesmo código do emissor. Uma das coisas interessantes da chamada diversidade cultural, alteridade, etc., é que você já sabe que o outro pode ler o mundo segundo sua própria cultura, o que envolve riscos, evidentemente. Esse é o meu ponto de vista.

\section{Quais os principais desafios para os estudos semióticos?}

Acredito que o futuro dos estudos semióticos necessita de três condições sine qua non: futuro, semiótica e estudo. Vivemos num momento muito especial. Vou utilizar um termo horrível, mas se trata de um período de altíssima semioticidade. Lotman, por exemplo, toma a Idade Média e diz que o medievo é uma cultura de altíssima signicidade. Em uma cultura como a nossa, curiosamente, quais são os termos, digamos, semióforos, que estão aparecendo? Pós-verdade, fake news, transpolítica... Em virtude de todos esses elementos, estamos em uma situação que requer, digamos, uma análise de como funcionam os signos.

Acredito que a flecha do tempo interno da semiótica está olhando para trás. Não digo que é um problema de nostalgia mas, sim, que fizeram toda a superação do passado, tal como os futuristas no século passado, como o termo indica, como uma espécie de superação em que o passado era um obstáculo. Quando chega a pós-modernidade, por exemplo, o passado começa a ser retomado como ironia, basta verificar as apostilas sobre 0 Nome da Rosa, de Umberto Eco. 0 passado é apenas uma caixa de Pandora em que eu pego o que me interessa. 0 futuro já não me preocupa, não me interessa, então, declinamos o presente. 0 problema é que esse presentismo atual tomou outras dimensões. É um presente com memória. É um presente com ativos, que busca o patrimônio. Nunca, na história, fizeram tantos museus que, na verdade, não se sabe bem se são mausoléus ou dispositivos mnemotécnicos. Os elementos de retorno ao passado não são um problema de nostalgia ou 
melancolia, mas são constitutivos do próprio presente. A relação com o campo, a natureza, o autêntico são uma forma de recuperar elementos anteriores.

Sabemos que não há nada mais único em virtude da produção em série, ou, da própria internet. Porém, busquemos o autêntico, a consolação da perda de unicidade para, digamos, nos salvaguardar da produção em série de qualquer coisa. Por isso, a intervenção da semiótica é clara, pois as competências de um sujeito das novas tecnologias não podem se restringir a likes. Temos que buscar a interatividade não em função da conexão, mais, sim, da relação. Quando Eco disse que a televisão era para os pobres e a internet para os ricos, queria dizer que, graças à televisão, muita gente aprendeu um monte de coisas, se alfabetizou, passou a conhecer o que existia em outras partes do mundo, em outros continentes. Qualquer um que estava isolado em uma pobreza extrema tinha condição de ver o mundo. Por outro lado, a internet é para os ricos porque todos que dispõem de um capital simbólico e cultural podem usá-la, e isso é uma maravilha. Porém, quando não se sabe usá-la, pode-se ficar preso pela grosseria, pela banalização, pela excrecência, etc.

Muitos viram nessa afirmação uma posição aristocrática de Umberto... Ao contrário! Ele estava muito preocupado com a educação, de que era preciso cooperar com o texto, ser um leitor modelo da internet, e não apenas satisfazer o ato de utilização de um texto com um like, com um referendo ou como uma decodificação simples. Uma tipologia cultural hoje nos permitiria ver os ensinamentos de Lotman não apenas no que se refere aos códigos, mas também no que diz respeito à atitude ante aos signos. Como disse Paolo Fabbri, dispomos de nossa caixa de ferramentas para entender esse cenário. Sabemos que não há uma volta ao passado, mas, sim, uma orientação temporal para recuperar um passado, uma espécie de simulacro de exceção de tanto simulacro. Hoje, o presentismo não é apenas um presente dilatado e eterno. É um presente que necessita recuperar, via a memória, todos os elementos que o constituem. Por isso, insisto, tudo é patrimônio, tudo é coleção, tudo é museu...

Memória histórica, museus, construção, coleções, preservação da natureza são coisas fundamentais para salvaguardar o planeta. 0 problema é quando o conservadorismo se faz conservador em conservar a natureza, até chegar ao ponto de criar falsos dissimulacros. 0 problema, por exemplo, da verdade... Não basta perceber que estamos em uma pós-verdade, o importante é saber quais os elementos que dispomos para a crítica. Acredito que o futuro 
da semiótica está relacionado ao futuro da crítica, ao futuro da análise, ao futuro do estabelecimento das diferenças e da pertinência.

\title{
The semiotician of history: an interview whit Jorge Lozano
}

\begin{abstract}
In this interview, Jorge Lozano, professor at the Department of Journalism and New Media at the Complutense University of Madrid, talks about his conception of history as a discursive construction and a historical document from a semiotic perspective. According to him, pertinence allows us to determine whether a particular cultural text may or may not function as a document. He also discusses his partnership with Umberto Eco and the importance of the "model reader" idea in the work of the Italian author and the relevance of this update concept to understand digital media. Finally, he explains how semiotics can contribute to construct an intelligibility of the present and the political dimension that involves any practice guided by understanding how signs function in culture.
\end{abstract}

\section{Keywords}

Semiotics. Historical Speech. Model Reader. Umberto Eco.

Recebido em 01/07/2019

Aceito em 02/07/2019 